\title{
ICT and the future of tourist management
}

\section{Karen Hughes and Gianna Moscardo}

Karen Hughes is based at the UQBS, University of Queensland, Brisbane, Australia.

Gianna Moscardo is based at the College of Business, Law and Governance, James Cook University, Townsville, Australia.
Received 14 December 2018 Revised 11 March 2019 Accepted 1 April 2019

(c) Karen Hughes and Gianna Moscardo. Published in Journal of Tourism Futures. Published by Emerald Publishing Limited. This article is published under the Creative Commons Attribution (CC BY 4.0) licence. Anyone may reproduce, distribute, translate and create derivative works of this article (for both commercial and non-commercial purposes), subject to full attribution to the original publication and authors. The full terms of this licence may be seen at http:// creativecommons.org/licences/by/ 4.0/legalcode

\begin{abstract}
Purpose - The purpose of this paper is to speculate how recent and emerging trends in information and communication technology (ICT) could change the way tourism businesses and organizations communicate with and manage their guests.

Design/methodology/approach - This paper applies elements of futures and design thinking to analyze current tourism management practices and identify critical touchpoints that link tourist decisions to management strategies.

Findings - Fictional travel stories were used to identify and analyze how technology might affect tourism through five touchpoints- choice, connection, co-creation, customization and compliance. These stories were analyzed to identify changing forces and suggest potential paradigm shifts that tourism managers need to consider. These included increasingly complex content, the importance of compatible connections, and the critical role of coordination and cooperation in future tourism systems.

Originality/value - While there have been numerous discussions of how tourists and tourism businesses access and use technology, there is little evidence of scholars and practitioners applying formal futures thinking to ICT and tourism. This paper used design thinking and stories to predict and illustrate ways in which technology could be embedded into tourism experiences and services. It suggests that technology can, and probably will, fundamentally change the way in which we manage tourists and their experiences.

Keywords Tourist management, Emerging ICT, Stories, Internet of Things, Futures thinking, Design thinking Paper type Research paper
\end{abstract}

\section{Introduction}

"We always overestimate the change that will occur in the next two years and underestimate the change that will occur in the next ten. Don't let yourself be lulled into inaction." In this commonly cited quote, the Founder of Microsoft, Bill Gates, is urging organizations to be more future-oriented in the way they plan for technology adoption and manage change (Weil, 2008). These sentiments are especially pertinent to tourism, as thinking about and planning for future change has been identified as a major weakness in both tourism research and practice (Yeoman, 2012), particularly in relation to information and communication technology (ICT).

Use of computers and other digital technologies is rapidly evolving. The widespread uptake of mobile devices enables access to multiple sources of information in a ubiquitous, continuously connected environment. The ways in which organizations change and respond to new technology are commonly categorized into three stages (Rainie and Wellman, 2012). In the first or substitution stage, organizations use new technology to automate or do existing tasks more efficiently (Contractor and Bishop, 2000). In the second or enlargement stage people learn to use the new technology to increase both the volume and complexity of existing tasks (Contractor and Bishop, 2000). Through this learning process users begin to recognize new possibilities and new opportunities before moving into the third or reconfiguration phase where the "new technology fundamentally changes the nature of the things it was created to address" (Rainie and Wellman, 2012, p. 297). It is in this third phase that systems experience significant innovation and disruption and organizations face strong competition from those who have adapted more quickly to the changes (Rainie and Wellman, 2012).

The challenge for tourism organizations is to find ways to think ahead to this reconfiguration phase and anticipate the changes that might be required to respond to possible transformations in their markets, processes and systems. The existing literature on ICT and tourism has tended to 
focus on the adoption, use, and evaluation of specific technologies, generally arguing for greater use of technology in tourism, usually with a substitution or enlargement claim. While some recent papers have begun to give attention to the potential for ICT developments to produce disruptive and transformative change (Gretzel, Sigala, Xiang and Koo, 2015; Gretzel, Werthner, Koo and Lamsfus, 2015; Werthner et al., 2015), to date there appears to be no systematic attempt to analyze tourism futures with regard to ICT. Additionally, scholars have tended to focus on implications for tourism supply with only limited attention paid to tourist decisions. What has not been explored to date is the possibility that advances in ICT are highly likely to change the way tourists contact and interact with suppliers. This paper seeks to address these gaps by combining elements of both futures and design thinking approaches to develop a conceptual framework focused on the touchpoints that link tourists and tourism suppliers, and by using stories to highlight how ICT may transform and disrupt these touchpoints.

\section{Futures thinking, design thinking and stories}

Much academic research in tourism looks backwards, providing detailed descriptions of the past and adhering to very traditional communication formats (Sheldon et al., 2011). Futures thinking usually seeks to present ideas about what could happen in the future "to stimulate thinking around key issues" (Varum et al., 2011, p. 100). It has been argued in other areas that if academics want to look forward and study futures and innovation they need to develop not only new methods but also be more innovative in the way they present the resulting knowledge (Gobble, 2014). Analyses of effective futures thinking in both general and tourism contexts consistently conclude that "best practice" approaches are based on mapping and analyzing existing systems; critically examining current assumptions, ideas and practices; and building scenarios or stories of the future (Inayatullah, 2008; Page et al., 2010; Yeoman, 2012).

Design thinking is concerned with presenting ideas about what should happen in the future to guide innovation. Design thinking suggests paying greater attention to analyzing user intentions and evaluations, advocating the use of stories (Brown, 2009) and combining creativity and science for more effective innovation (Goes, 2014). Stories are particularly effective for engaging with and presenting information to key stakeholders (IDEO, 2012). User stories have also been used in futures thinking about ICT in general (cf. Atzori et al., 2014). Given their complementary goals, it is not surprising that descriptions of futures and design thinking offer a similar set of steps and tools for analysis and presentation (Goes, 2014).

Inayatullah's (2008) Six Pillar model offers five steps for futures thinking that was adapted for this paper. An overview of the futures/design thinking approach used is presented in Figure 1. The first step involved mapping the present by briefly reviewing current approaches to researching tourism and technology adoption. Second, a deeper systems analysis using a story was conducted. This focused on identifying critical touchpoints where tourist goals connect to management actions. Third, the emerging technologies most likely to cause transformation in tourism were described. Fourth, the touchpoints were used to organize a future user story highlighting likely paradigm shifts within tourism management. Finally, the paper presents possible challenges and barriers to change.

\section{Step one: reviewing current tourism ICT research}

A review of current research into ICT and tourism was conducted focusing on papers published in the Journal of Information Technology and Tourism between 2010 and 2017, and papers presented at ENTER conferences. These were supplemented by a search through Google Scholar and the major electronic databases of Proquest, Science Direct, Emerald Insight and Sage Journals, which collectively cover all the major journals in tourism including the Journal of Tourism Futures. This second part of the search used the search phrase "ICT tourism review" and variants such "information technology tourism review," and "technology tourism review" in order to focus attention on a broader level of analysis.

Eight major themes emerged from this review:

1. describing and or advocating the use of different ICT options to do existing tasks better; 


\begin{tabular}{ll}
\hline $\begin{array}{l}\text { Steps Proposed For } \\
\text { Futures Thinking }\end{array}$ & Steps used in this paper \\
\hline Mapping the present & $\begin{array}{l}\text { Review of current } \\
\text { tourism ICT research }\end{array}$ \\
Deeper Systems Analysis & $\begin{array}{l}\text { Using a story to map } \\
\text { current tourist } \\
\text { management systems and } \\
\text { identify critical } \\
\text { touchpoints }\end{array}$ \\
Anticipating Disruptions & $\begin{array}{l}\text { Overview of emerging } \\
\text { and predicted ICT } \\
\text { development }\end{array}$ \\
$\begin{array}{l}\text { Forecasting and Creating } \\
\text { Scenarios }\end{array}$ & $\begin{array}{l}\text { Using stories to predict } \\
\text { paradigm shifts in } \\
\text { tourism management }\end{array}$ \\
Identifying barriers to \\
change
\end{tabular}

2. profiling which tourists use ICT and how tourists use ICT;

3. examining user experience and evaluations of ICT applications in tourism;

4. studying tourist organizations' adoption and use of ICTs;

5. researching data analytics;

6. discussing technical and design features of, and improvements to, specific technologies;

7. exploring the role of ICT in tourist experience enhancement and co-creation; and

8. analyzing the concept of smart tourism and smart tourism destinations (Law et al., 2014; Liang et al., 2017; Navío-Marco et al., 2018; Standing et al., 2014; Wang et al., 2010; Yuan et al., 2018).

As noted previously, while many ICT and tourism papers suggest ICT has the potential to fundamentally change the nature of tourism and tourism business structures, few have attempted to systematically map out likely changes.

\section{Step two: using a story to identify critical touchpoints}

The next step in futures analysis is analyzing current systems and processes. It is rare to find information on how tourists interact with and connect to the supply components of a destination (Pearce, 2016). The lack of a widely accepted tourism management system model necessitated use of an alternative approach to analyze management processes and systems. Stories were chosen for two reasons. First this approach is commonly used in both design and futures thinking to link user experiences to management actions (Brown, 2009; IDEO, 2012). Second, tourists' stories are emerging as an important research and analysis tool because they provide important insights into tourist management issues (Moscardo, 2017a; Woodside, 2010).

The story presented below provides an insight into the key elements of destination experiences as a system and highlights common decisions tourists need to make, types of problems they 
have to solve, and touchpoints where they come into contact with supply components. These touchpoints are identified in brackets, and discussed after the story:

The Bennett family has been planning their short break for many weeks. Together they have planned an itinerary that includes three nights in a beachside luxury resort in a tropical location [Choice]. Mr and Mrs Bennett are looking forward to exploring the local art gallery, while Josh and Ella (aged 9 and 11) excitedly discuss the nearby jungle walk to deserted temple ruins and how it sounds just like the setting of one of their favourite Adventure Dan online games.

They check in and click through the online menus on their TV. Mrs Bennett has special dietary requirements and makes a booking at a restaurant where the menu looks like it might accommodate her requirements [Choice]. They adjust the room's air-conditioning so that it will be nice and cool on their return [Customization], then head out to the nearest art gallery, ignoring the sign asking them to save energy by turning everything off when they leave the room [Compliance].

At the art gallery they explore the art on offer, learning about the local artists from the labels and listening to an audio visual presentation on the role of the environment in inspiring the exhibition. The kids are restless - they have been promised the jungle walk that afternoon if they behave but really, there's nothing much of interest for them here [Customization]. The kids' audio trail is boring and the activity centre only has colouring-in sheets and video games [Customization]. Mrs Bennett thinks it would be lovely to meet another family with children of similar ages so the kids could have someone to play with [Connection]. Mr Bennett thinks it might be nice to meet some of the local artists and get more connected to the local community and its culture [Connection].

They return to the hotel for a short siesta in the air-conditioning, then set off on their walk. The kids excitedly push past each other trying to be the first to the ruins. Mrs Bennett has to constantly remind them to stop to read the signs. Together they discuss who might have made the path and how they did it - none of the signs seem to mention this [Customization]. Mrs Bennett gets flustered about making sure the kids stay on the path - it's quite steep in places but luckily there are fences to stop them getting too close to the edge [Compliance]. Mr Bennett isn't too pleased though - the barriers spoil his scenic photographs and intrude on his quiet contemplation of nature [Customization].

Once at the temple, the kids climb all over the walls, ignoring the safety signs at the bottom [Compliance]. They're both really excited to be exploring ancient ruins in the jungle like Adventure Dan. They wonder who built the temple and what it would be like for the explorer who had actually discovered this temple [Customization]. They plead with Mr and Mrs Bennett to buy them paint from the gift shop so they can help colour-in a large frieze of Adventure Dan propped up near the temple walls [Co-creation] but Mrs Bennett isn't interested and Mr Bennett is too hot and bothered. Perhaps another day...

This user based story highlights the interface or touchpoints where tourists' problems, activities and decision-making connect with points of supply:

- making choices or decisions about the next course of action such as finding an appropriate restaurant or planning an activity;

- customizing activities, services and experiences to meet personal needs, circumstances and interests;

- complying with safety and minimal impact directives such as staying on paths and not climbing on walls;

- seeking to build connections, either to enhance in-group relationships by ensuring a balance of activities that appeal to all members, or to meet other people such as the local artists or families with children; and

- co-creating experiences that are personally meaningful, engaging and memorable.

Inayatullah (2008) refers to the process of identifying underlying goals and functions as deepening and argues that this process focuses attention on core areas for futures analysis and change strategies. In the Bennetts' holiday story, the five touchpoints identified (choice, customization, compliance, connections and co-creation) provide a way to think about tourist experiences and management systems that progresses beyond simply describing the elements in the current system. 


\section{Step three: describing emerging and predicted ICT development}

In 2013, the McKinsey Global Institute identified a set of disruptive technologies predicted to significantly alter the way we think, work and play. Table I provides a summary of technologies most likely to affect tourism. These have considerable scope to influence a broad range of industries, products and services; have the potential to create substantial economic impact; are advancing rapidly; and are likely to change how we view and interact with the world (Manyika et al., 2013).

Many areas of tourism are likely to be impacted and changed by disruptive technologies. Mobile communication devices help travelers to navigate through unfamiliar terrain and to connect with a broad range of tourism providers. They allow tourists to create itineraries "on the run" by providing access to websites, apps and social media sites that offer travel information, booking services and user recommendations. ICTs will allow greater sharing of recommendations from travelers with similar characteristics, motives and preferences. In the future, networks of travelers could be the primary source of hints and advice, with location-based services enabling travelers connect with others in their current surroundings who can provide "real time" advice on things to see and do. As Lamsfus et al. (2015) argue, internet access is virtually ubiquitous which allows people to connect to their social networks and networks of others who may be present in the same time and space. At the moment, social media networks send alerts when someone in your network is in the same vicinity. In the future, we may be able to expand our networks by inviting likeminded others in our immediate vicinity to share our experiences. For example, traveling families could connect to locals with similar aged children to share experiences and resources; or link back to family and friends back home who could simultaneously experience their travels using AR technology.

Digital technologies have already allowed organizations to develop experiences where the virtual world responds to tourists' actions. To illustrate, the Disney company has developed technology that places weight sensors in cakes so that when a guest takes a slice, butterflies (images projected on the cake) are released (Mine et al., 2012). Augmented Reality can superimpose

Table I Disruptive technologies

Technology

Mobile communication devices (MCDs) (smartphones, tablets, smart watches)

Location-based services

The Internet Of Things

Augmented reality

Sematic web
Dimensions

Allow access to online search engines, information, booking services, apps, social media platforms. Change the way in which humans understand and interact with each other and their surroundings (Manyika et al., 2013)

Enable organizations and individuals to track and communicate with people based on their geographical location to provide information and services tailored to a particular point in time and space, and responsive to current conditions and situations (e.g. weather, crowding, bookings, special offers). Core element in pervasive computer games, where the spatial movement of participants in the real world is fundamental to how the game is played and scored online. These networks of players create experiences that evolve from participants' responses, position and mood (Linaza et al., 2013) Use of smart sensors in multiple objects in environments that independently collect and share information (Gubbi et al., 2013). Can track and collect information, relay this to networks for analysis, then share and/or act upon that information facilitating effective management and use of resources and spaces (Manyika et al., 2013) Allows the user to see the real world and a super-imposed augmented virtual world simultaneously, creating dynamic environments that "come to life" (Mine et al., 2012). Most current applications focus on visual senses but AR focusing on others senses are likely to become more common (Wang et al., 2013)

Uses algorithms based on previous behavior and preferences to identify and provide individualized content users are likely to want to see (Moreau, 2016) 
images of the past (architecture, furnishings, events) over what is currently visible; headsets and helmets combine computer generated sounds with sounds in the immediate surroundings; and hand-held devices and/or gloves can respond to touch and pressure (Jung et al., 2015).

The key challenge here is that the proliferation of information may hinder rather than enhance tourists' understanding and decision making. One strategy to help tourists cope with the increasing volume of information and possible choices is the use of semantic tagging and programming to customize information more closely to individual preferences. Many websites already offer additional information and advertisements to tourists based on their patterns of search and use. As sensors embedded in the Internet of Things and data analytic algorithms become more sophisticated and accurate in measuring consumer behaviors, commercial provision of information and advertisements will become more closely aligned to an individual's needs and preferences. Apps are already able to track tourists' movements; inform them when they're in the proximity of favorite brands, events and social contacts; and provide directions and recommendations (Lua et al., 2015). Tagging could also be used to direct people's movements. Currently, site managers use a combination of physical environmental design (fences, walkways) and persuasive communication (e.g. signs, brochures, guides), sometimes supported by threat of penalty, to guide tourist behavior in areas where safety and negative impacts are a concern (Mason, 2005). In the future, these functions could be allocated to onsite sensors linked to the Internet of Things. These could be programed to send vibrating or audible warning when tourists stray into dangerous or prohibited areas or engage in undesirable actions.

\section{Step four: using stories to understand the forces for change}

This step used a futures thinking approach that incorporated the ideas of Raven and Elahi (2015) on the use of stories and narrative in futures analysis. The touchpoints identified earlier (choice, customization, compliance, connections and co-creation) were combined with current and emerging ICT trends to predict how tourism management might look in the future. These predictions were then used to generate a story that illustrates the use of emerging technologies to manage and enhance the Bennett family's holiday:

\footnotetext{
At the beginning of the year the Bennett family registered their interest in a June mini-break and three weeks ago got notification that their dream holiday was available! Bookings for hotels, tours and activities that match holidays they have taken previously are on hold if they wished to take up the offer [Customization]. They decide to go! Mr and Mrs Bennett are looking forward to exploring the local art gallery that has been sending them pod casts [Customization], while Josh and Ella (aged 9 and 11) excitedly discuss the nearby jungle walk to deserted temple ruins that feature as the background in their favourite Adventure Dan online games.
}

On arrival, the robot receptionist accesses their cloud-based guest profiles - no need for tedious forms and procedures - and programs their in-room TV to provide multi-sensory menus from near-by restaurants [Choice]. The automatic Skype connection with each restaurant allows Mrs Bennett to talk to the chef about her dietary requirements and custom-design something suitable for that night [Customization]. As they leave for the art gallery, room sensors turn off the air-conditioning and lights [Compliance].

Sensors in the art gallery retrieve their profiles from their mobile devices and suggest a route through the space that would best suit each of their tastes. As they wander through, each family member receives different information, stories and questions through their Alexa connected headphones [Customization]. Then they all receive a message that a family with similar demographics and taste has entered the gallery - would they like to meet up so the kids can do a treasure hunt together? [Connection] Mr Bennett has concentrated his visit on galleries displaying contemporary artwork and declines because he's just received a message that his favourite artist is part of a live-stream broadcast in the gallery's sensory dome and he has lots of questions he wants to ask her [Customization].

The kids and the mums meet up [Connection] and spend the next hour happily looking for the "treasure" in certain art works. They adjust the colours and composition of each painting by holding up their mobile devices, giving it instructions and seeing it change on screen [Customization]. This provides much entertainment, especially as their Snapchat glasses allow them to share their "new" paintings with their social media networks [Connection]. 
After lunch, the family sets off on their walk with their new friends [Connection]. The kids excitedly push past each other trying to be the first to the ruins. As the families reach points of interest, their mobile devices vibrate to alert them to audio and/or visual information about the place [Customization]. Together they discuss who might have made the path and how they did it - their wearable devices interpret the conversation and almost immediately the answers start to appear. Mr. Bennett doesn't really want this information so he turns that function off on his device [Choice]. The path is quite steep in places but sensors activate loud warning sounds if anyone gets too close to the edge [Compliance]. Mr Bennett is happy because there are no fences to spoil the view and the feeling of being in nature [Customization].

As they approach the complex, they receive notification that a large tour group is currently onsite; consequently, a secondary path is now open - taking this will ensure that by the time they reach the main temple, the group will have left [Customization]. Suddenly, the path lights up - it's an Adventure Dan hologram inviting them to don their portable AR headsets to explore the temple with him! Using their AR headsets, they are able to see, hear and smell what the temple would have looked like when it was first discovered 200 years ago. Adventure Dan invites the children to take on the role of their favourite character, and together they act out a story about discovering hidden treasure [Co-Creation]. The kids are particularly intrigued that Adventure Dan knows so much about their tastes and preferences [Customization]. This is so cool and they don't need an adult to play! Their parents start to relax - each child is tagged through their devices so it's easy to see where they are on the online interactive site map. They also know that onsite cameras and sensors will prevent the kids climbing the walls or doing anything silly [Compliance].

Just as she's wondering how to spend the next hour or so, Mrs Bennett is delighted to receive an invitation on her mobile device from the tribal chief to hear the story of the temple's creation - exactly what she's interested in! [Customization]. She pops on her Snapchat glasses so she can livestream the experience to her best friend at home [Connection]. Mr Bennett wants a more solitary experience. He turns his device to "quiet contemplation" mode and wanders through the site listening to relaxing music [Choice].

That evening, Josh and Ella download a recording of their Adventure Dan experience that features them as the lead characters in their very own story [Co-Creation]. They can't wait to post this to the Adventure Dan online community for other gamers to enjoy and comment on [Connection]!

The changing forces within tourism management that have been highlighted in this story are summarized in Figure 2. This is a positive scenario in which the predicted technologies enhance

Figure 2 Predicted paradigm shifts in approaches to tourism management

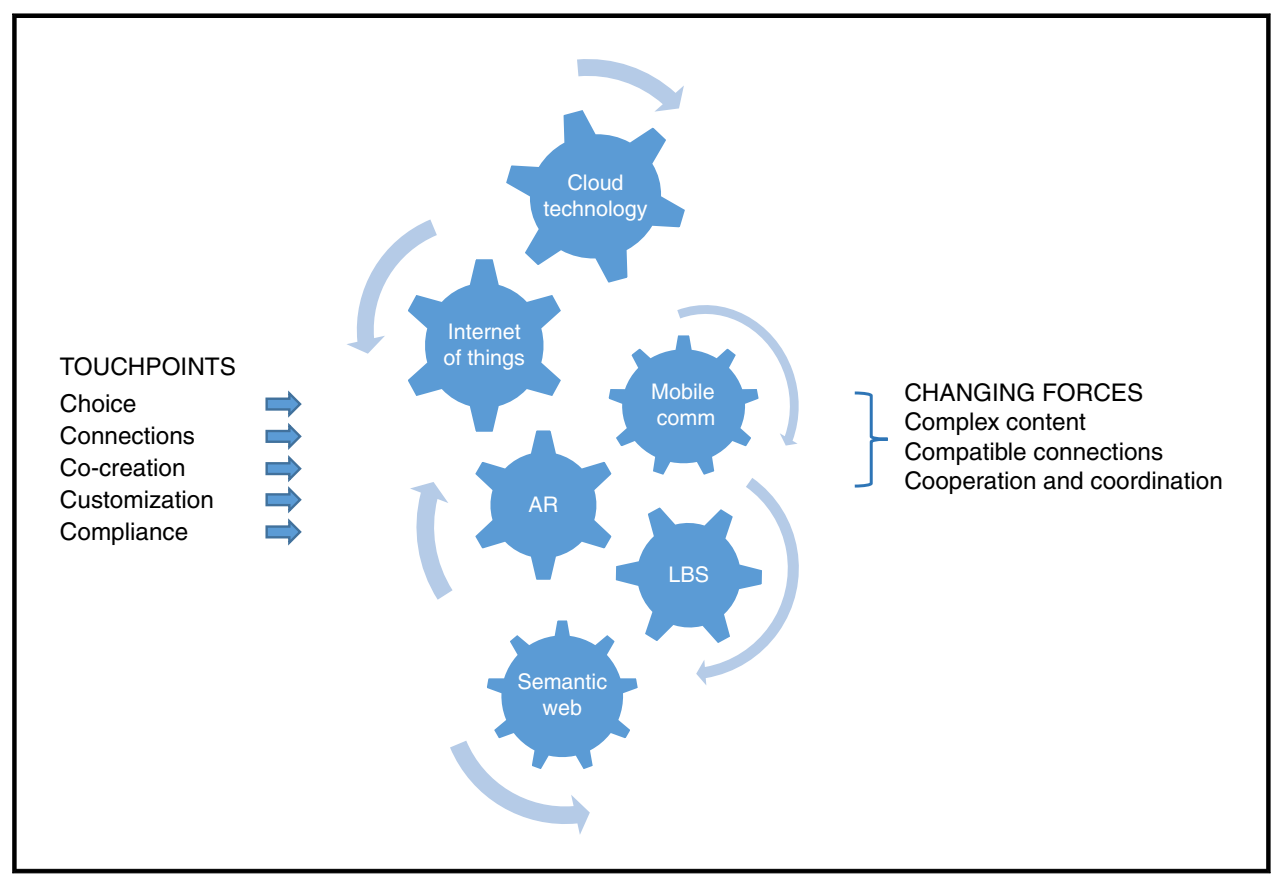


the visitor experience along a number of dimensions. It is possible to generate a number of alternative scenarios ranging from a very negative one in which the predicted technologies detract from all dimensions of the experience through to scenarios in which the technology is sometimes a positive force and sometimes a negative one. It is also possible to extend this analysis to include features beyond the immediate visitor experience in some detail including pre-travel decision making and post-travel reflection. Unfortunately space restrictions in a single paper exclude detailed examination of all these alternatives. The choice to focus on a positive scenarios reflect the strong focus in the existing tourism and ICT literature on highlighting how these predicted technologies will enhance tourism. Negative or critical analyses of ICT and tourism are extremely rare. The choice to focus on the tourist or visitor experience rather than on other travel phases was based on a desire to explore this aspect of tourism in more detail as the existing literature mentions it but generally focuses on tourism organization and processes not directly linked to the tourist experience. Thus the aim was to use the existing literature, which is about enhancement and to add to that literature by examining the tourist experience in more detail.

Figure 2 provides a preliminary conceptual framework for the further analysis of these changing forces on tourist experiences. An examination of the tourism literature found no existing general models, frameworks or theories of tourist management as a system or set of interconnected processes. There are numerous texts on tourism management that have implicit models expressed in the topics covered and the order of that coverage, but they are about tourism more broadly and are typically oriented toward setting out supply side components. In these approaches tourists are markets to be attracted, customers to be served, or potential sources of negative impacts with each of these being seen as separate activities (Pearce, 2016). These tourism management approaches do not provide information on how tourists interact and connect to the supply components of destination (Pearce, 2016), or how they manage themselves. The story supported the development of preliminary model of tourism management that connects tourism businesses to tourists through a set of critical touchpoints that in turn are likely to be changed significantly by emerging and predicted technologies.

The authors now examine these changing forces in more detail, paying particular attention to backstage tourism management changes that would be needed to support the future tourist story. A key feature of emerging technologies is the proliferation and complexity of content available for both tourists and tourism managers. Every aspect of the future story is based upon the generation and use of complex content about the sites, the Bennetts, and other tourists. This suggests a level of knowledge and data collection and manipulation far beyond what is currently considered as user-generated content. Considerable sophistication in the use of data analytic results will be required (Gretzel et al., 2015).

While connectivity is a key theme in discussions of the emerging and predicted technologies, this focus is almost exclusively on the connectivity between devices and between devices and their immediate users. The connections critical touchpoint and the future story alert us to the changing ways in which tourists connect to other people. In future, these types of connections could be more immediate in both time and space and made based on more complex judgments of compatibility between the people being connected (Werthner et al., 2015). While new businesses such as AirBnB and Uber are often cited as disruptions (Gretzel et al., 2015), they are arguably simply a new type of intermediary connecting tourists to providers. The possibility of connection without any intermediaries could be much more disruptive, especially in terms of changing the power relations amongst providers at a destination (Atzori et al., 2014).

One notable absence in the future tourism story is lack of any immediate contact with, or use of services from, a destination marketing organization (DMO). Currently DMOs identify markets, advertise, provide information about destination businesses and assure service quality. These activities are already becoming obsolete (Wang et al. , 2013), consequently DMOs are increasingly engaging in alternative functions such as coordinating smart infrastructure, data analytics, and disseminating knowledge to destination stakeholders (Buhalis and Amaranggana, 2014).

The ability of tourists to connect directly to other tourists, destination residents and small specialized tourism businesses supports tailored customization and extensive co-creation of experiences. A future tourism world that offers complex choices, customized experiences, 
compatible connections and opportunities for co-creation assumes a high level of cooperation and coordination amongst tourism providers.

Cooperation is not just about creating meaningful tourist experiences. The future tourism story also highlights potential ways in which tourist site and attraction managers might be able to use the new technologies to encourage compliance with safety directions and minimal impact behaviors. The story describes the absence of onsite physical structures such as gates, fences and signs to provide safety and support onsite experiences. Moscardo (2017b) notes that over time there have been changes in interpretive practice and theory toward a strong focus on managing tourist pressure on heritage places. The ability of emerging technologies to take on these tasks will require a significant change in the way interpreters think about their roles. The future story presented here is a hopeful one in which site managers and tourists cooperate in ways that support safety and minimize negative impacts on the site. This vision is based on a level of cooperation between the tourists and the site managers that requires much less direct control from managers. A less hopeful story might have cooperative compliance replaced by more severe management control.

The future tourism story also highlights the extensive automation that could happen in tourism. Such automation could make many current tourism employees redundant, an outcome acknowledged in general discussion of ICT futures (Anderson et al., 2014) but not given much attention in ICT and tourism. While this creates immediate concerns for the endangered tourism employees, it should also create concern at a broader level as in many destinations, residents only tolerate the negative social, cultural and environmental impacts of tourism because of the employment it generates.

The future travel experience described in the Bennett story also assumes the existence, coordination, maintenance and management of the required infrastructure and systems, a common assumption in many ICT futures scenarios (Rose et al., 2015). In these new systems value is created and exchanged in new ways (Gretzel et al., 2015). Emerging business opportunities include the design, creation, installation and maintenance of the infrastructure and systems (Anderson et al., 2014), and services to assist users to navigate complex systems (Atzori et al., 2014).

In addition to the assumption that the required infrastructure and systems to support these new technology-based tourist experiences exist, is the assumption that all tourism providers have the capacity to effectively use these systems. Required capabilities has been discussed in both the general ICT literature as well as the ICT and tourism literature. The most commonly listed required skills are mastering and managing complexity and constant change, IT literacy, knowledge management, network management and continuous learning strategies (Atzori et al., 2014; Manyika et al., 2013).

In the predicted future tourism world, businesses will not sell intangible service elements, but rather offer specific skills, services and capacities to tourists creating their own experiences, or to other providers in dynamic, flexible informal networks (Manyika et al., 2013). Such providers would need to be able to identify what they have that is of value to others in the network. They will also need to be able to engage in and manage multiple relationships within complex networks. This will require considerable sophistication in cooperation, knowledge sharing and coordination skills (Gretzel et al., 2015).

\section{Step five: identifying constraints, challenges, concerns, cautions}

The rapid emergence and evolution of technical innovations can be seen as a double-edged sword. Some organizations and destinations will embrace new technologies and the potential they offer; others may not be ready for this change and may find it difficult to operate in a system that no longer follows traditional rules and practices (Pedrana, 2014). There are a number of constraints and challenges associated with using ICTs to manage tourists. These include:

- Organizational reluctance to use technology. Purchasing, installing and maintaining equipment, then training staff to effectively use and manage these systems, is expensive and time-consuming (Manyika et al., 2013). Where businesses choose not to adopt new technologies they may create frustration for tourists who want to use new technologies and systems in places where these are not supported. 
- While computers may make some tasks more efficient, tourism is a people-based industry where the quality of customer service often determines tourist satisfaction. Replacing staff with computers, introducing self-service for tasks such as hotel check-in and meal ordering, and booking every element of tourists' itinerary prior to arrival may remove the interpersonal and spontaneous elements of travel. Tourists who want the personal touch may go elsewhere. Any introduction of computer-based solutions to management issues needs to consider the importance of functional benefits vs personal/emotional engagement.

- Some businesses and organizations may resist sharing information as it limits their control over the content (Proctor, 2010).

- The many opportunity for tourists to connect amongst themselves may circumvent the need for formal tourism providers, thus fundamentally changing the key players as well as the nature of relationships in tourism experiences.

- Privacy and security issues are a genuine concern, particularly if data are stored permanently. The Internet of Things and supporting Cloud technology raises questions about the use and dissemination of data that have been collected and stored with or without people's knowledge or permission. Identity protection and possible security and infiltration of the network for criminal or terrorist purposes are also concerns (Gubbi et al., 2013; Manyika et al., 2013). Recent studies of young adults revealed that Gen $Y$ and Gen Z are particularly concerned about war, terrorism and political conflict, and that these concerns are more evident amongst young adults living in developed economies than those living in emerging economies (Coca-Stefaniak and Morrison, 2018). Given that these are the tourists of the future, issues related to personal safety, cyber security and cyber terrorism need to be taken into consideration when designing and implementing ICT solutions to managing tourist destinations and tourists.

- The same systems that collect data and monitor behavior could also be seen as surveillance that supports control over that behavior (Anderson et al., 2014); not all tourists will appreciate this.

- As technologies continue to evolve and advance, there's a possibility that people will replace real travel with augmented reality experiences. While this could help mitigate the challenges of managing tourists in fragile, remote and/or over-crowded destinations, it may create new problems in terms of attracting sufficient people to particular places.

\section{Conclusions: to infinity and beyond}

The existing discussion of ICT and tourism has mostly focused on ways in which new technologies can automate or make existing tasks more efficient (doing old things better) or ways that expand and alter existing tasks (doing old things in new ways). For many organizations the real challenge lies in trying to think ahead to what happens beyond these options, what new things are going to emerge and what fundamental changes might ensue (Contractor and Bishop, 2000; Rainie and Wellman, 2012). Futures and design thinking are both areas that offer methods for systematically examining this third stage with the aim of stimulating thinking about what could or should happen in the future. The ability to generate potential future scenarios or stories is critical for developing proactive strategies to engage with these options (Yeoman, 2012).

Although papers in ICT and tourism often talk about the possibility of declines in areas and the emergence of new businesses, few have offered specific details. The present paper expands upon this discussion by highlighting the potential for the loss of many of the current jobs in tourism in a number of areas and the need for DMOs to carefully consider their role in tourism. Studies are needed to explore how technology-driven experiences and services influence tourists' perceptions and satisfaction - can technology really be used in roles that have for many generations been delivered by humans? If the answer is affirmative, studies to identify which sectors of the industry are particularly well-suited for ICT solutions will be required. The paper also identifies a number of areas for new business and employment opportunities. The challenge now is to take these possible paradigm shifts and seek practitioner responses. 
Although the focus of the paper was on tourism management practice, the potential paradigm shifts identified also generate issues for tourism educators. Tourism educators need to revisit key features of curricula to ensure that they actually do build skills in knowledge management, systems thinking, cooperation and coordination, and lifelong learning. These are all areas that will be vital for tourism management in the future but have been noted as deficient in current tourism education approaches (Sheldon et al., 2011). Imagine the Bennetts in the future - maybe tourism management will have nothing to do with marketing destinations and experiences, or managing visitor behavior in-situ:

Slogging through the snow to her front door, Mrs Bennett gets notification on her mobile phone that next weekend the local travel complex will be featuring her first preference, The Great Barrier Reef. Delighted, she confirms the booking. That Saturday, the family check into the complex and change into their summer clothes. It's hot and slightly humid in their personal AR theatre - just what they ordered! Mr Bennett pulls an icy cold beer from the in-house fridge, and settles into the lounge chair to watch the "waves" breaking on the shore and read his online newspaper. The kids plunge into the waves, delighting at the cool refreshing water that they feel on their AR wetsuits. They ask if they can swim to the furthest life buoy - Mrs Bennett nods happily as she lies back onto her towel. She knows that they won't actually physically move from the room and that by the time they have tired themselves out, she'll have a lovely all-over tan as a reminder of the relaxing day.

But maybe the Bennetts don't even need to travel to the complex - AR travel rooms may become a feature of homes in the future. These rooms could show AR places of the Bennett's choice; alternatively, they could show livestream footage from people in their social networks who are currently traveling. With a flick of a switch, the room could convey the temperature, smells and sounds of "their" traveler's physical environment. The Bennetts can see exactly what their friend sees and can talk to them during the experience, all from the comfort of their own home.

\section{References}

Anderson, J., Rainie, L. and Duggan, M. (2014), "The internet of things", available at: www.pewinternet.org/20 14/05/14/internet-of-things/ (accessed February 10, 2017).

Atzori, L., lera, A. and Morabito, G. (2014), “'From' smart objects'to' social objects”, IEEE Communications Magazine, Vol. 52 No. 1, pp. 97-105.

Brown, T. (2009), Change by Design, Harper Collins, New York, NY.

Buhalis, D. and Amaranggana, A. (2014), "Smart tourism destinations", in Xiang, Z. and Tussyadiah, I. (Eds), Information and Communication Technologies in Tourism 2014, Springer, Cham, pp. 553-64.

Coca-Stefaniak, A. and Morrison, A.M. (2018), "City tourism destinations and terrorism - a worrying trend for now, but could it get worse?”, International Journal of Tourism Cities, Vol. 4 No. 4, pp. 409-12.

Contractor, N. and Bishop, A. (2000), "Reconfiguring community networks", in Ishida, T. and Isbister, K. (Eds), Digital Cities, Springer, Berlin, pp. 151-64.

Gobble, M. (2014), "Design thinking”, Research Technology Management, Vol. 57 No. 3, pp. 59-62.

Goes, P. (2014), "Editor's comments", MIS Quarterly, Vol. 38 No. 1, pp. iii-viii.

Gretzel, U., Sigala, M., Xiang, Z. and Koo, C. (2015), “Smart tourism”, Electronic Markets, Vol. 25 No. 3, pp. 179-88.

Gretzel, U., Werthner, H., Koo, C. and Lamsfus, C. (2015), "Conceptual foundations for understanding smart tourism ecosystems", Computers in Human Behavior, Vol. 50, September, pp. 558-63.

Gubbi, J., Buyya, R., Marusic, S. and Palaniswami, M. (2013), "Internet of things (loT)", Future Generation Computer Systems, Vol. 29, pp. 1645-60.

IDEO (2012), "Design thinking for educators", available at: www.designthinkingforeducators.com/DTtoolkit_ v1_062711.pdf (accessed January 10, 2016).

Inayatullah, S. (2008), "Six pillars: futures thinking for transforming”, Foresight, Vol. 10 No. 1, pp. 4-21.

Lamsfus, C., Wang, D., Alzua-Sorzabal, A. and Xiang, Z. (2015), “Going mobile”, Journal of Travel Research, Vol. 54 No. 6, pp. 691-701.

Law, R., Buhalis, D. and Cobanoglu, C. (2014), "Progress on information and communication technologies in hospitality and tourism", International Journal of Contemporary Hospitality Management, Vol. 26 No. 5, pp. 727-50. 
Liang, S., Schuckert, M., Law, R. and Masiero, L. (2017), "The relevance of mobile tourism and information technology”, Journal of Travel \& Tourism Marketing, Vol. 34 No. 6, pp. 732-48.

Linaza, M., Gutierrez, A. and García, A. (2013), "Pervasive augmented reality games to experience tourism destinations", in Xiang, Z. and Tussyadiah, I. (Eds), Information and Communication Technologies in Tourism 2013, Springer, Berlin, pp. 497-509.

Lua, J., Maob, Z., Wanga, M. and Hu, L. (2015), “Goodbye maps, hello apps?”, Current Issues in Tourism, Vol. 18 No. 11, pp. 1059-79.

Manyika, J., Chiu, M., Bughin, J., Dobbs, R., Bisson, P. and Marrs, A. (2013), Disruptive Technologies, McKinsey Global Institute, San Francisco, CA.

Mason, P. (2005), "Visitor management in protected areas”, Current Issues in Tourism, Vol. 8 Nos 2-3, pp. 181-94.

Mine, M., van Baar, J., Grundhofer, A., Rose, D. and Yang, B. (2012), "Projection-based augmented reality in Disney theme parks", Computer, Vol. 45 No. 7, pp. 32-40.

Moreau, E. (2016), "What is web 3.0 and is it here yet?", available at: www.lifewire.com/what-is-web-3-03486623 (accessed February 10, 2017).

Moscardo, G. (2017a), "Stories as a tourist experience design tool”, in Fesenmaier, D. and Xiang, Z. (Eds), Design Science in Tourism, Springer, Basel, pp. 97-124.

Moscardo, G. (2017b), "Critical reflections on the role of interpretation in visitor management", in Albrecht, J. (Ed.), Visitor Management in Tourist Destinations, CABI, Wallingford, pp. 170-90.

Navío-Marco, J., Ruiz-Gómez, L. and Sevilla-Sevilla, C. (2018), "Progress in information technology and tourism management”, Tourism Management, Vol. 69, December, pp. 460-70.

Page, S., Yeoman, I., Connell, J. and Greenwood, C. (2010), "Scenario planning as a tool to understand uncertainty in tourism", Current Issues in Tourism, Vol. 13 No. 2, pp. 99-137.

Pearce, D. (2016), "Interdependent destination management functions", Tourism Recreation Research, Vol. 41 No. 1, pp. 37-48.

Pedrana, M. (2014), “Location-based services and tourism”, Current Issues in Tourism, Vol. 17 No. 9, pp. 753-62.

Proctor, N. (2010), "Digital”, Curator, Vol. 53 No. 1, pp. 35-43.

Rainie, L. and Wellman, B. (2012), Networked, MIT Press, Cambridge, November.

Raven, P. and Elahi, S. (2015), "The new narrative”, Futures, Vol. 74, pp. 49-61.

Rose, K., Eldridge, S. and Chapin, L. (2015), "The internet of things", available at: www.internetsociety.org/ sites/default/files/ISOC-loT-Overview-20151022.pdf (accessed February 20, 2017).

Sheldon, P., Fesenmaier, D. and Tribe, J. (2011), "The tourism education futures initiative (TEFI)", Journal of Teaching in Travel \& Tourism, Vol. 11 No. 1, pp. 2-23.

Standing, C., Tang-Taye, J. and Boyer, M. (2014), "The impact of the internet in travel and tourism", Journal of Travel \& Tourism Marketing, Vol. 31 No. 1, pp. 82-113.

Varum, A., Melo, C., Alvarenga, A. and Soeiro de Carvalho, P. (2011), "Scenarios and possible futures for hospitality and tourism", Foresight, Vol. 13 No. 1, pp. 19-35.

Wang, D., Fesenmaier, D., Werthner, H. and Wöber, K. (2010), "The journal of information technology and tourism", Information Technology \& Tourism, Vol. 12 No. 1, pp. 3-16.

Wang, X., Kim, M., Love, P. and Kang, S. (2013), "Augmented reality in built environment", Automation in Construction, Vol. 32, July, pp. 1-13.

Weil, N. (2008), "The quotable Bill Gates", available at: http://abcnews.go.com/Technology/PCWorld/story? id=5214635 (accessed November 10, 2016).

Werthner, H., Alzua-Sorzabal, A., Cantoni, L., Dickinger, A., Gretzel, U., Jannach, D..... and Zanker, M. (2015), "Future research issues in IT and tourism", Information Technology \& Tourism, Vol. 15 No. 1, pp. 1-15.

Woodside, A. (2010), "Brand-consumer storytelling theory and research", Psychology \& Marketing, Vol. 27 No. 6, pp. 531-40.

Yeoman, I. (2012), 2050-Tomorrow's Tourism, Channel View, Bristol.

Yuan, Y., Tseng, Y. and Ho, C. (2018), "Tourism information technology research trends", Tourism Review, Vol. 74 No. 1, pp. 5-19, doi: 10.1108/TR-08-2017-0128. 


\section{About the authors}

Dr Karen Hughes is Senior Lecturer at the University of Queensland, Australia and researches and teaches in the area of sustainable tourism, tourist behavior and visitor management. Her research focuses on the areas of interpretation, environmental education and using stories to connect with new and emerging visitor markets. In 2009 Karen completed a PhD exploring the impacts of post-visit support on families' conservation learning at Mon Repos turtle rookery. She is currently working on several research projects investigating the impact of interpretation on visitors' long-term environmental knowledge, attitudes and behavior. Dr Karen Hughes is the corresponding author and can be contacted at: k.hughes2@uq.edu.au

Dr Gianna Moscardo is Professor in the College of Business, Law and Governance at James Cook University, Australia. Her research interests include evaluating tourism as a sustainable development strategy with an emphasis on understanding the relationships between characteristics of tourism development and dimensions of destination community well-being. She is also interested in understanding tourist behavior and experiences, the effectiveness of tourist interpretation and the role of stories in tourist experience design. Dr Moscardo has authored or co-authored more than 200 international, peer reviewed academic publications. Dr Moscardo is the current Chair of the Building Excellence in Sustainable Tourism Education Network (BEST EN), an international organization committed to the creation and dissemination of knowledge to support the sustainable tourism education, research and practice.

For instructions on how to order reprints of this article, please visit our website:

www.emeraldgrouppublishing.com/licensing/reprints.htm

Or contact us for further details: permissions@emeraldinsight.com 